Structure of Malonogalactan :

\section{Carbon-13 Nuclear Magnetic Resonance Spectra of Malonogalactan}

\author{
Masaru Ogura, Tomoaki Kohama, * \\ Masao Fujimoto, Akira KuninaKa, \\ Hiroshi Yoshino and Hiroshi SugIYama** \\ Research Laboratory, Yamasa Shoyu Co., Ltd., \\ Choshi ${ }^{* *}$ Chemical Research Institute \\ of Non-Aqueous Solution, \\ Tohoku University, Sendai
}

Received June 28, 1974

In previous papers, ${ }^{1 ; 2}$ it was shown that the malonogalactan obtained from Penicillium citrinum Thom 1131 was a 1,5- $\beta$-galactofuranoside polymer esterified with malonic acid at the $\mathrm{C}-2$ or $\mathrm{C}-3$ position and consisted of D-galactose and malonic acid in the approximate molar ratio of $3: 1$. In this note, the configuration of the malonogalactan is further elucidated by ${ }^{13} \mathrm{C}$ NMR spectrometry, and it is concluded that the galactofuranoside polymer was esterified with malonic acid at the C-3 position. ${ }^{13} \mathrm{C}$ NMR spectra were obtained on a Hitachi R-26 spectrometer operating in the Fourier transform mode at $10.0 \mathrm{MHz}$.

The proton noise-decoupled ${ }^{13} \mathrm{C}$ NMR spectra of the malonogalactan and the galactan (demalonylated malonogalactan) in $\mathrm{D}_{2} \mathrm{O}$ shows that they were homogeneous polysaccharides (Fig. 1). In the ${ }^{13} \mathrm{C}$ NMR spectrum of the galactan (Fig. 1A), the peak at $108 \mathrm{ppm}$ for the anomeric carbon seems to correspond to the peak of the C-1 carbon of 1,2-trans furanosides, because, $\mathrm{T}$. Usui et al. ${ }^{3)}$ recently proposed that the peak of the C-1 carbon of the 1,2-trans methyl furanosides (about $109 \mathrm{ppm}$ ) shifted downfield by $5 \sim 6 \mathrm{ppm}$ from that of the 1,2-cis methyl furanosides (about 104 ppm). Therefore the anomeric carbons are confirmed to be involved in $\beta$-linkage. The peak of the $\mathrm{C}-5$ carbons of furanosides was reported to appear at $60 \sim$ $65 \mathrm{ppm}^{3 \sim 61}$ So the peak of the $\mathrm{C}-5$ carbon of the $\beta$-galactofuranoside should appear at $68 \sim 72 \mathrm{ppm}$. In the Penicillium galactan, however, the peak of the C-5 carbon was found to shift downfield to 77.5 or $78 \mathrm{ppm}$. This fact suggests that the $\mathrm{C}-5$ carbons were involved in the glycosidic linkage. Thus, the galactan is concluded to contain exclusively $\beta \quad 1 \rightarrow 5$ linkages. This conclusion coincides with the result in our previous paper. ${ }^{21}$

* Present address: Department of Bacteriology, Tohoku University School of Medicine, Sendai.
(A)
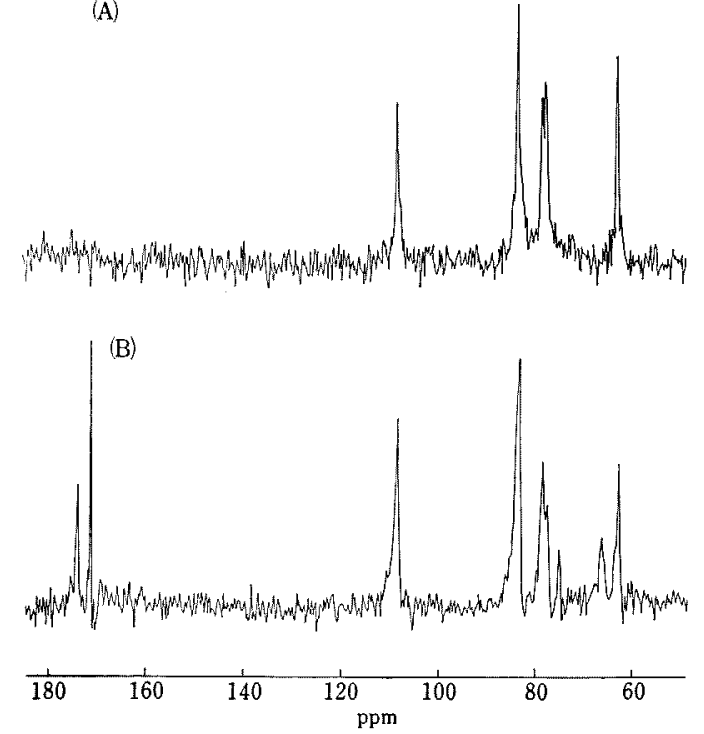

Fig. 1. C-13 NMR Spectra of the Galactan (A) and Malonogalactan (B).

The other carbons were assigned in comparison with the methyl $a$-L-arabinofuranoside. ${ }^{31}$ The peaks at 62.5 and either of 77.5 and $78 \mathrm{ppm}$ could be assigned to the $\mathrm{C}-6$ and $\mathrm{C}-3$ carbons, respectively. The peak at $83 \mathrm{ppm}$ had an increased intensity and could be assigned to the overlapped peaks of the $\mathrm{C}-2$ and $\mathrm{C}-4$ carbons. In the ${ }^{13} \mathrm{C}$ NMR spectrum of the malonogalactan (Fig. 1B), the peaks of the galactose moiety were identical with those of the galactan.

We reported already that the malonogalactan was esterified with malonic acid at $\mathrm{C}-2$ or $\mathrm{C}-3$ position.21 If the esterified position were $\mathrm{C}-2$, the peak of the $\mathrm{C}-2$ carbon should be observed in the lower filed than that of the galactan. However, such shift was not observed in the ${ }^{13} \mathrm{C}$ NMR spectrum of the malonogalactan (Fig. 1B). So the esterified position was concluded to be $\mathrm{C}-3$. The peak of the $\mathrm{C}-3$ carbon bonded to the esterified oxygen shifted to $83 \mathrm{ppm}$ from $77.5 \mathrm{ppm}$ and it was overlapped with the peaks of the $\mathrm{C}-2$ and $\mathrm{C}-4$ carbons. The peak of $77.5 \mathrm{ppm}$ in the malonogalactan was smaller than that in the galactan, so it seems reasonable to assign the peaks of 77.5 and $78 \mathrm{ppm}$ to the $\mathrm{C}-3$ and $\mathrm{C}-5$ carbons, respectively.

In the ${ }^{13} \mathrm{C}$ NMR spectrum of the malonogalactan, 4 peaks $(66,76,171.5$ and $174 \mathrm{ppm})$ due to the carbons of the malonic acid moiety were recognized. Among them, the peaks at 171.5 and $174 \mathrm{ppm}$ could be assigned to the ester-carboxyl carbon and the free carboxyl carbon, respectively. ${ }^{4} \quad$ The signal intensity of the peak at $171.5 \mathrm{ppm}$ (the ester-carboxyl carbon) was much stronger than the peak at $174 \mathrm{ppm}$ (the free carboxyl carbon). Thus, there is a possibility that some of the 
Table I. Carbon-13 Chemical Shifts ${ }^{a}$,

\begin{tabular}{|c|c|c|c|}
\hline & $\begin{array}{l}\text { 1-Methyl } \\
\text { L-arabino } \\
\text { furanoside }\end{array}$ & Malono- & Galactan \\
\hline $\mathrm{C}-1$ & 109.5 & 108 & 108 \\
\hline$C-2$ & 82.0 & 83 & 83 \\
\hline $\mathrm{C}-3$ & 77.9 & 83 and 77.5 & 77.5 \\
\hline $\mathrm{C}-4$ & 84.8 & 83 & 83 \\
\hline $\mathrm{C}-5$ & 62.5 & 78 & 78 \\
\hline$C-6$ & - & 62.5 & 62.5 \\
\hline Ester-carboxyl C & - & 171.5 & 一 \\
\hline Methylene C & - & 66 and 76 & - \\
\hline Free carboxyl C & - & 174 & - \\
\hline
\end{tabular}

malonic acid residues have the diester linkage in the malonogalactan, although it is generally dangerous to compare the signal intensity of peaks in proton noisedecoupled FT ${ }^{13} \mathrm{C}$ NMR spectra. If this possibility is correct, the remaining peaks at 66 and $76 \mathrm{ppm}$ would be assigned to the methylene carbon of the malonic acid monoester and that of the diester, respectively. The methylene signal of free malonic acid appears at $41 \mathrm{ppm}$ and the $\alpha$-carbon signal of ester usually appears somewhat upper field than that of free acid. ${ }^{4}$ Those peaks at 66 and $76 \mathrm{ppm}$ appear at extremely low field as the $\alpha$-carbon signal and can be assumed to have the average chemical-shifts of the high-speed tautomerism of keto- enol $\left(\mathrm{sp}^{3} \underset{\sim}{\longrightarrow} \mathrm{sp}^{2}\right)$. Hence, there should be two kinds of malonic residue in the malonogalactan, and the peak at $76 \mathrm{ppm}$ would be assigned in the malonic acid diester, as the enol type is assumed to be more predominant in the diester than in the monoester. Probably, the resulted diester bridges would not be intermolecular but intramolecular, because the malonogalactan is very soluble in water $(>500 \mathrm{mg} / \mathrm{ml})$.

On the basis of the ${ }^{13} \mathrm{C}$ NMR spectra, whose chemical shifts are summarized in Table $I$, the malonogalactan is concluded to be a polysaccharide that has $\beta \quad 1 \rightarrow 5$ linkage and is esterified with malonic acid at the position of 3 .

Acknowledgement. We thank gratefully Mr. Yasuo Wada, Naka Works, Hitachi, Ltd., for kindly measuring the ${ }^{13} \mathrm{C}$ NMR spectra.

\section{REFERENCES}

1) M. Fujimoto, S. Yonei, T. Kohama, A. Kuninaka and H. Yoshino, Agr. Biol. Chem., 33, 1666 (1969).

2) T. Kohama, M. Fujimoto, A. Kuninaka and $\mathbf{H}$. Yoshino, ibid., 38, 127 (1974).

3) T. Usui, S. Tsushima, N. Yamaoka, K. Matsuda, K. Tuzimura, H. Sugiyama, S. Seto, K. Fujieda and G. Miyajima, ibid., 38, 1409 (1974).

4) J. B. Stothers, "Carbon-13 NMR Spectroscopy," Academic Press Inc., New York, 1972, pp. 148, pp. 296 and pp. 467.

5) E. Breitmaier, G. Jung und W. Voelter, Chimia, 26 (1972) Nr. 3 (Marz) 136.

6) E. Breitmaier and W. Voelter, Tetrahedron, 29, 227 (1973). 